\title{
Productivity Optimization in a Shopping Complex using Industrial Engineering and Facility Layout Planning Tools
}

\author{
Omkar Gijare, Shubham Khaire, Mohd. Yasin Bagwan, Sahil Srivastava, Venugopal Kulkarni
}

\begin{abstract}
Due to constant supply and demand cycles of grocery, food, dairy \& other everyday products in the shopping complexes, there is no provision available for revision of existing Standard Operating Procedure (SOP) to evaluate its productivity. The productivity of a shopping complex can be determined in terms of sales, utilization of material, machine and manpower, energy utilization and amount of waste utilized. The aim of this paper is to study existing SOP and plant layout in order to suggest modifications through scientific methods which will reflect in optimized productivity. This study implicates material handling processes and equipment as well. The methodology followed belongs to industrial engineering and facility planning tools and techniques. Layout redesigning is performed following the guidelines of various facility planning experts. Work study, time study is performed under observation of teaching professional and the management of the complex. The improvements emphasize on areas where occurrence of problems is more frequent and wastage amounts are very high. Knowing the fact that various factors such as infrastructure, building and capital constraints are inevitable in redesigning the total plant layout, the improvements suggested achieve increased productivity while following all regulations and limitations. This study will not only provide a betterment to the functioning od that complex, but it will provide guidelines for newly undertaken studies and projects.

Keywords: Facility planning, Material handling equipment, Method study, Productivity, Shopping complex
\end{abstract}

\section{INTRODUCTION}

It is frequently observed that in many shopping malls and complexes, though the resources are more than sufficient, a large share of them is wasted due to lack of management attention. The reluctance to change is also a reason behind such wastages even if the improvements are suggested by their customers.

Revised Manuscript Received on April 15, 2020.

* Correspondence Author

Omkar Gijare, School of Mechanical \& Civil Engineering, MIT Academy of Engineering, Pune, India. Email: omgijare@gmail.com

Shubham Khaire, School of Mechanical \& Civil Engineering, MIT Academy of Engineering, Pune, India. Email: shubhamkhaire@mitaoe.ac.in

Mohd. Yasin Bagwan, School of Mechanical \& Civil Engineering, MIT Academy of Engineering, Pune, India. Email: mbbagwan@mitaoe.ac.in

Sahil Srivastava, School of Mechanical \& Civil Engineering, MIT Academy of Engineering, Pune, India. Email: srsrivastava@mitaoe.ac.in

Prof. Venugopal Kulkarni, School of Mechanical \& Civil Engineering, MIT Academy of Engineering, Pune, India. Email: vpkulkarni86@gmail.com

(C) The Authors. Published by Blue Eyes Intelligence Engineering and Sciences Publication (BEIESP). This is an open access article under the CC BY-NC-ND license (http://creativecommons.org/licenses/by-nc-nd/4.0/)
Therefore, it is an industrial engineer's responsibility to point out such improvements and to arrange implementation to achieve optimum productivity by reducing wastage and thus increasing efficiency of resources.

It is to be understood that the term productivity, when applied to a functioning organization such as shopping mall, becomes complex in nature. The productivity of a shopping mall can be calculated by analyzing the satisfaction of its customers, job satisfaction of its employees, usage of resources such as water and electricity supply, total sales etc. Although the productivity is defined as 'the ratio between volumes of output as measured by production indices to the corresponding volume of labour input as measured by employment indices' by International Labours Organization, in case of shopping malls, the optimal output is nothing but sales of the products through a fixed period of time. All the other factors are associated along with the sales while determining productivity.

This project was performed in a medium scale shopping complex located in Moshi, Pune where there was an opportunity to study the supply-demand cycle of various products along with the management and operation of a complex i.e. the path followed by the products from dispatching of the manufacturer to the buyer or consumer. The objective of the project was to bend towards optimum productivity by solving frequently occurring problems and modifying line of flow of products. In initial stages, the problems faced by customers and employees were as follows:

1. Single billing counter resulting in long rows and thus discomfort to the customers

2. Long paths to walk in order to reach to a product due to continuous and long shelves

3. Large amounts of wastages due to expired products

4. Discomfort to employees while refilling of shelves due to awkward body position

5. Long period of waiting time for customers due to blockages in the path at the time of refilling of shelves

6. Insufficient shelf-space for placing small-sized products.

In order to encounter these problems, revision and modification of current layout was crucial as many of the problems were indicating towards lack of facility planning and implementation. Also, to achieve employee satisfaction, modification is material handling equipment was important.

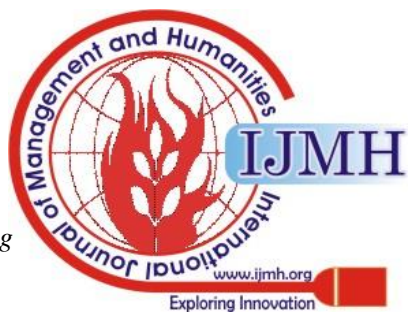


Here, one thing is be understood that the complex being studied is of medium-scale and hence there are no trolleys available for customers as there is no aisle space through which the trolleys can pass.

The walkways are not wide enough to carry trolleys. Hence customers need to carry plastic baskets to hold their products together.

\section{Objectives of the Research:}

- To achieve customer satisfaction which will reflect in increased sales

- To reduce wastages occurring due to expired products

- To achieve employee satisfaction by reducing their efforts while working

Reducing the expenses is also a method of achieving optimum productivity as the expenses over resources are nothing but input to the organization. In simple words, high productivity means maximum output in minimum amount of input. Hence, the scope of this study will be to minimize the input while achieving optimum number of satisfied customers.

\section{METHODOLOGY}

\section{A. Wastage Causing due to Expired Products:}

The management encountered this problem very frequently and the amounts of products passing expiry date was also high. It was very important to find out root cause of this problem as it was directly pointing towards employees' misconduct. It was their duty to place old products in front while placing newly arrived products in the back of the shelves. This practice was to be followed by each and every employee but still the amounts of expiring products was high. So, to achieve the root cause, 5WHY analysis was performed.

As shown in the figure 1, the First-In-First-Out, FIFO practice was inconvenient for employees to follow because of their awkward body position while refilling the shelves. It was not possible for them to bend down and arrange the products according to their expiry dates consistently hence the date-wise arrangement was neglected in some places.

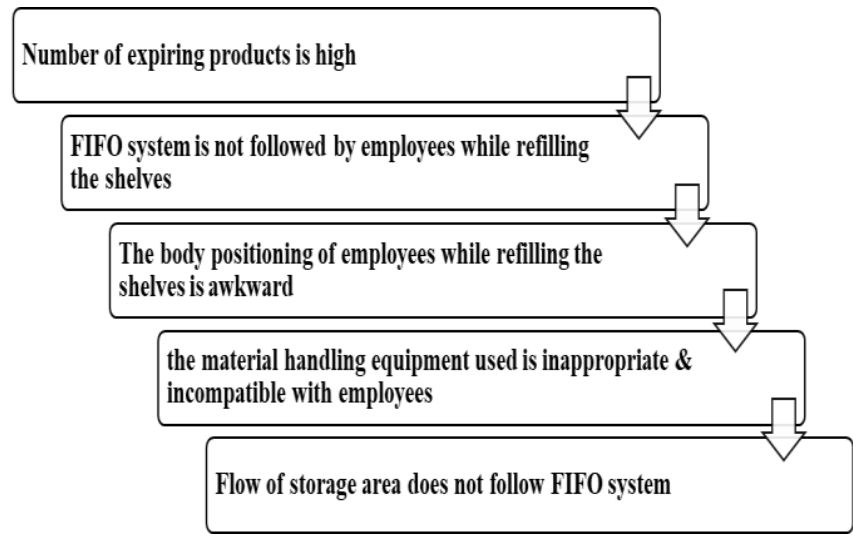

Fig. 1: 5WHY Analysis for root cause

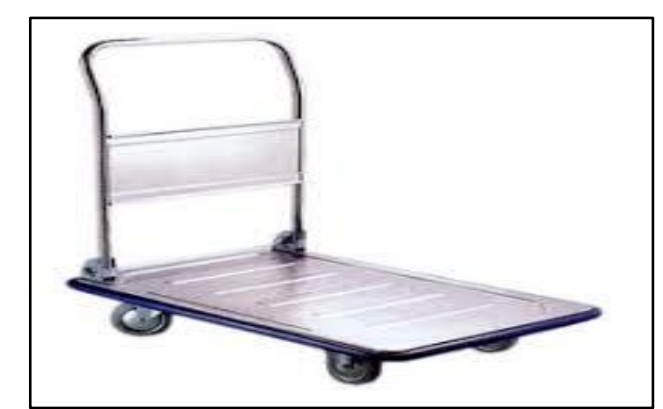

Fig.2: Existing material handling equipment

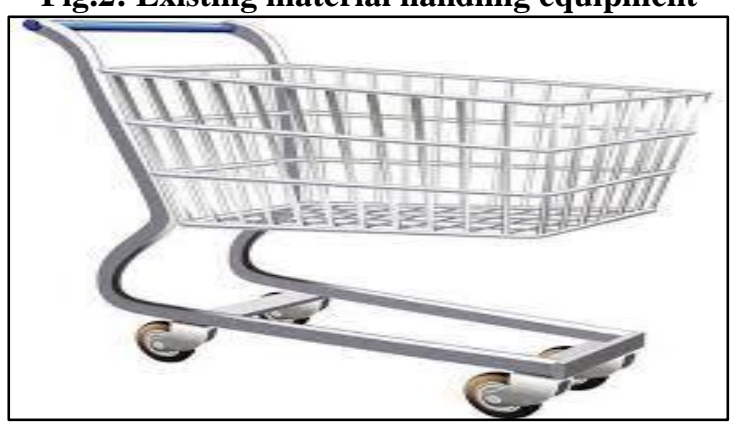

Fig.3: Proposed material handling equipment

As the 5WHY analysis suggests, the root cause behind the problem was the material handling equipment used was not compatible with the employees. As shown in the fig. 2, a trolley having its container at some specific height is able to eliminate bending of employees while refilling the shelves which will also reduce neglection of FIFO by them. Hence, a modified material handling equipment can solve the problem of expired products.

The 5WHY analysis also indicated that the picking of the boxes at the time of refilling is not appropriate as well. No FIFO is followed while picking the boxes to refill. To avoid this misconduct, a modification in layout of the storage area was required. As shown in the figure 3 , the storage area only had a single opening or only one pathway for both IN and OUT of the material. Because of that, the boxes of products were being selected randomly by the employees. To encounter this issue, if the proposed type of layout is implemented, the material will only be entering through path at the bottom and it will be OUT only through upper opening. Due to this practice, old material will be stacked on upper shelves only and it will be the first to be picked up. Thus, implementation of this layout will follow FIFO system of material handling and hence the wastage due to expired products will be avoided.

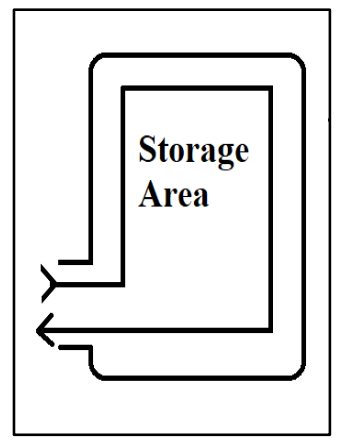

Fig. 4: Existing storage area layout

Published By:

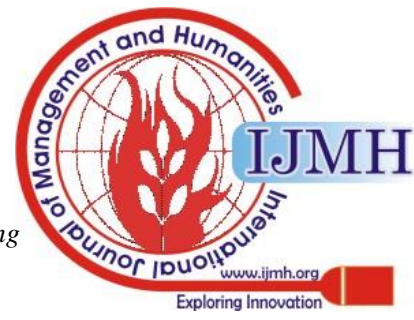




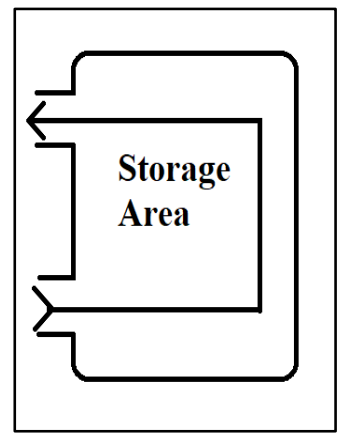

Fig. 5: Proposed storage area layout

In order to evaluate rise in productivity by these remedies, one shelf of food products where they were maintained thoroughly according to expiry dates and another shelf where products were placed vaguely, both were observed. After observation period of one week, four products from the maintained shelf expired whereas seventeen products from the other shelf found to be expired. Sixty products were placed on both the shelves and hence productivity can be calculated as follows:

Productivity of the shelf $=$ consumable products after one week/total products on shelf

Now, for maintained shelf, it is $56 / 60=93.33 \%$ and for the other shelf, it is $43 / 60=71.67 \%$

Hence, if the suggested improvements are implemented, an estimated rise in productivity is around $21.66 \%$.

\section{B. Pathway Blockages at the Time of Refilling of the Shelves:}

This problem is faced mainly by the customers and it is main reason behind many complaints the management comes across on daily basis. In the period when employees are busy refilling the shelves with products, customers are unable to reach a variety of products and they have to wait until the task of the employee is not accomplished. As the employees carry a trolley loaded with the boxes with them, whole pathway which is already narrow gets totally blocked and customers become unable to reach to their required products. If they require those products mandatorily, they need to walk around the shelf which is around six metres long which is obviously being the reason behind their discomfort. If the cleaning activities are going on, whole shelf becomes unavailable for shopping and due to such inconvenience, customers get irritated and they avoid to shop in this particular complex which results into drastic drops in sales and thus, productivity.

This may not seem a problem worth solving but while the study was under fulfilment, many of the customers stated this to be the key factor in the performance of any shopping complex. This small problem becomes the reason of arguments between customers and the employees and due to this, customer try to avoid shopping in such complexes.

In order to understand what refilling activity is and how much time it exactly needs, a flow process chart is to drawn after performing the method study. By observing into table I, the time of blocked pathway may be estimated to be around four minutes. This amount of time is affecting to each and every shelf whereas the cleaning activities are excluded in the table. Therefore, though the time period appears to be small but that small period of time costs into reluctance from the customers.
Table I: Flow Process Chart
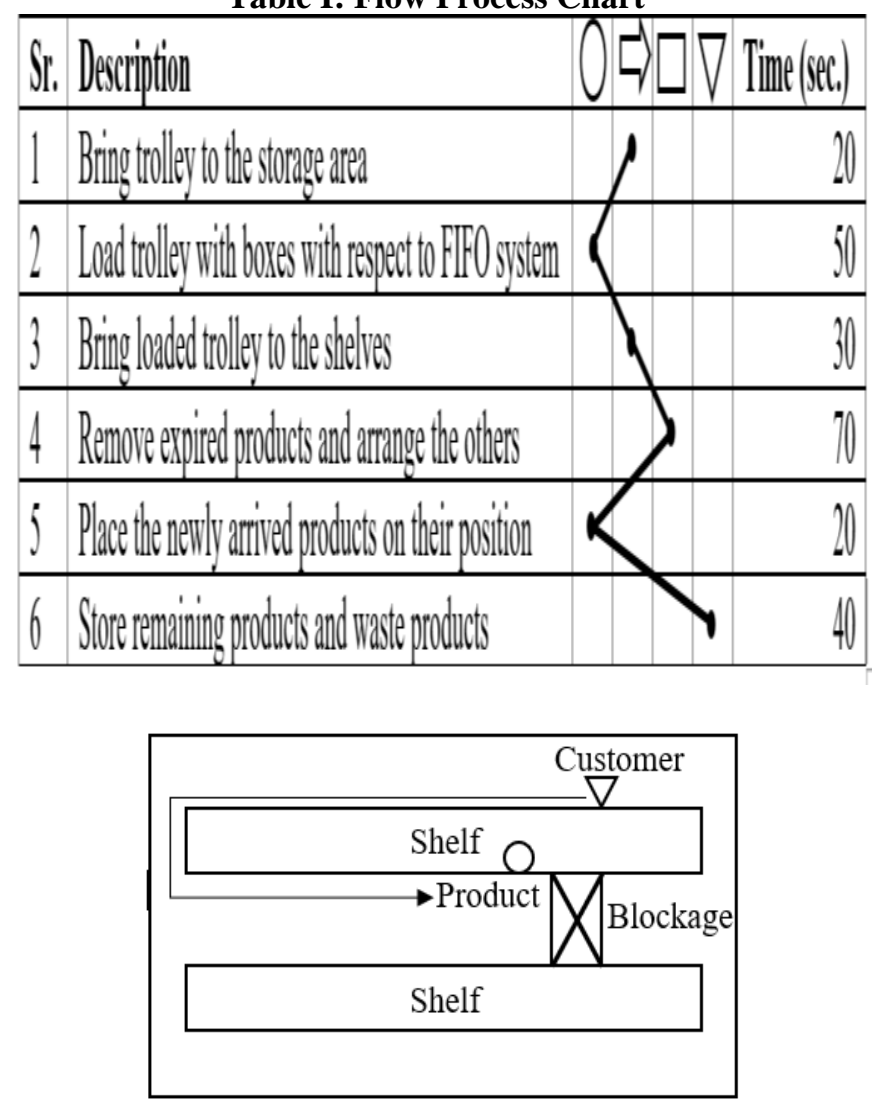

Fig. 6: Existing mall layout

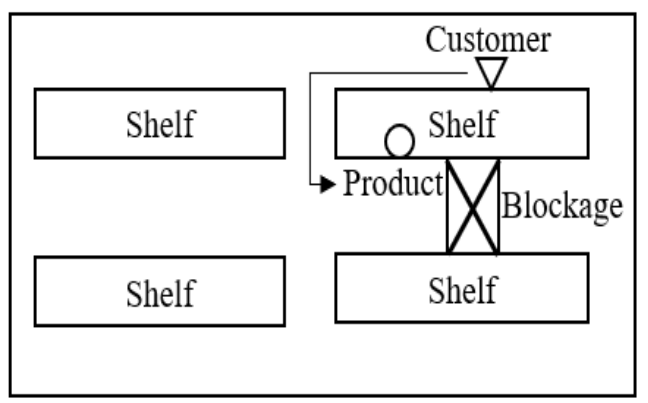

Fig. 7: Proposed mall layout

The solution to this problem is to modify the layout of shelves such that the long shelves will be divided into two parts creating a gap between the $m$ which will enable the customers to reach to their product in least distance and the blockage of complete shelf at the time of refilling will be eliminated. The gap created should be wide enough that a trolley should be passing through it easily and without any collision with any wall or surface.

Now, to calculate rise of productivity from this solution, the ratio of ideal distance from the customer to the product i.e. without blockage to distance travelled due to blockage is considered.

Productivity $=$ Ideal distance $\mathrm{w} / \mathrm{o}$ blockage $/$ distance travelled due to blockage

Now, in first case, productivity is 5.4/7.6=71.05\% whereas for second case, 5.4/6.2=87.09\%

Therefore, using this solution, a rise in productivity of $16.04 \%$ can be obtained. 


\section{Bottleneck due to Single Billing Counter:}

In the existing layout, there is a single entrance to the mall where customers need to submit their bags, helmets etc. and a single billing counter from where the customers check their goods out and pay the bill. Here, due to single billing counter, bottleneck was observed because of long procedure of billing. This phenomenon was causing loss of customers as the number of customers entered was relatively high if compared to number of customers attended. Hence, to avoid discomfort to customers causing due to waiting in queues carrying their heavy goods in a basket, an improvement is suggested to arrange two billing counters in order to achieve smooth unhampered flow of customers which will result into rise of sales. Inside the layout, the entrance counter is placed at the bottom left corner so that each and every customer automatically pass through it after checking out and this facility will provide return of their bags and other accessories. Now, to calculate productivity, one auxiliary counter was established on experimental basis along with one existing counter to analyse the rise in number of customers attended. To calculate productivity, the ratio of number of customers attended by the billing counter to the number of customers entered in the mall is determined. It is obvious that the remaining customers did enter the shopping complex but they did not buy anything due to long queue. This is the loss to complex which is hidden but it affects the sales directly.

Now, in case of single billing counter, a total of 46 customers were attended out of 63 customers entered into the complex. Therefore, productivity in this case $=46 / 63=$ 73.01\%.

When the two counters were fully functioning, a total of 69 customers were attended out of 85 customers who entered onto the complex on that particular day. Hence the productivity can be found out as $69 / 85=81.17 \%$.

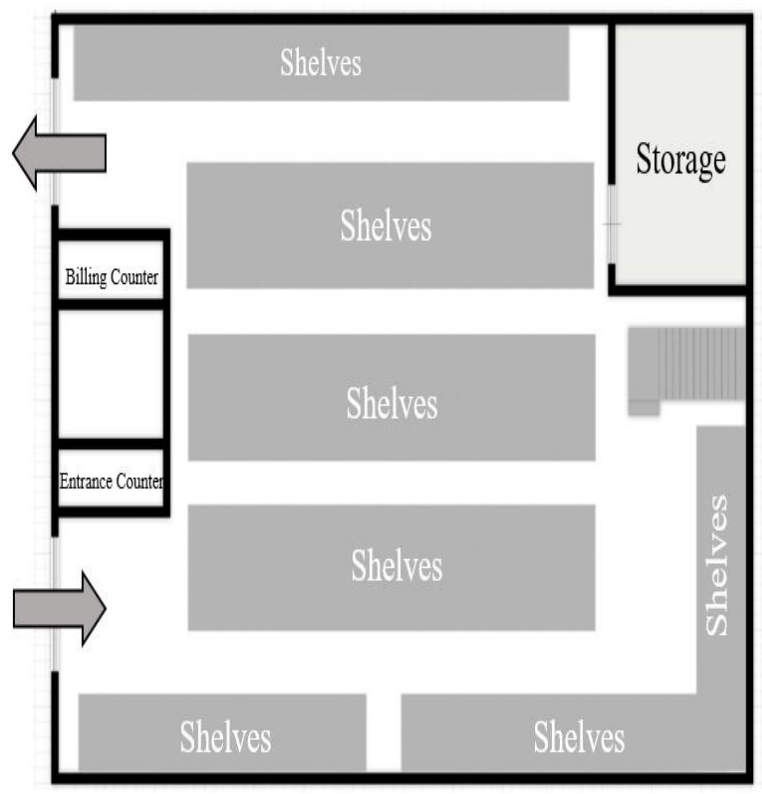

Fig. 8: Existing Layout

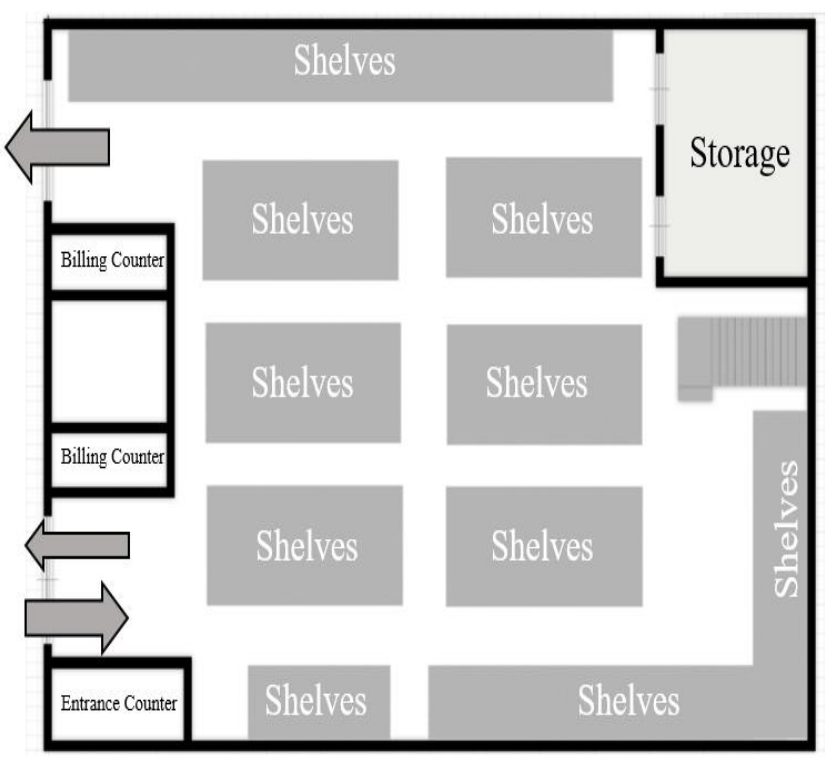

Fig. 9: Proposed Layout

\section{Result Analysis}

Table II: Increments in productivity

\begin{tabular}{|l|l|l|l|l|}
\hline Condition & $\begin{array}{l}\text { Wastage } \\
\text { due to } \\
\text { expired } \\
\text { products } \\
(\%)\end{array}$ & $\begin{array}{l}\text { Pathway } \\
\text { blockages } \\
(\%)\end{array}$ & $\begin{array}{l}\text { Bottleneck } \\
\text { due to } \\
\text { single } \\
\text { billing } \\
\text { counter } \\
(\%)\end{array}$ & $\begin{array}{l}\text { Average } \\
(\%)\end{array}$ \\
\hline Existing & 71.67 & 71.05 & 73.01 & 71.91 \\
\hline Modified & 93.33 & 87.09 & 81.17 & 87.20 \\
\hline
\end{tabular}

The increments in productivity due to all suggested improvements are illustrated in table II. Through this study, it is proven that the productivity is a function of customer as well as employee satisfaction, waste conservation and reduced efforts of both man and machine. Hence an overall rise of $15.3 \%$ can be observed in the productivity if all the improvements mentioned earlier are implemented and are maintained. This study emphasizes on small modifications in material handling, existing layout and the method followed in order to achieve optimum productivity with minimum investments in those improvements.

The improvement in productivity in determined in percentage whereas it is calculated using various quantities such as distance, time and unit products. All of these quantities may not be calculated in terms of money whereas to implement suggested improvements, direct cost factor turns up. So, it is important here to understand time value of money. Hence it is crucial for the management to understand the criticality of these problems and their solutions.

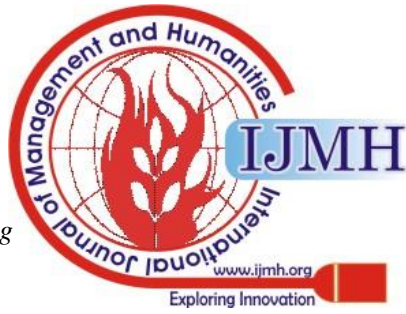


For example, while implementing the proposed layout, due to having an extra counter, the shelf showcase area is reduced by $1.75 \mathrm{~m} 2$ which reflects towards direct loss even after the implementation. Also, the cost of improves set of trolleys is much higher than existing trolleys (around 3200 INR). Hence it is important to segregate direct losses and hidden losses and the magnitudes of them so as to decide the suggestion is worth implementation or not.

\section{CONCLUSIONS AND DISCUSSIONS}

The performance of the improvements suggested is tested against the capital being invested in implementing them by creating temporary replication of all the improvements so as to identify their usefulness after permanent implementation. It is to be understood that the cost factor entirely affects selection of implementable suggestions. The implemented improvements are those which are cost effective along with the maximum capacity of increasing productivity.

Various other modifications were also suggested such as to change the position of employee restroom but due to large capital investment in implementation of such suggestions, those were excluded from the scope of this study. Correct application of work study, method study, i.e. industrial engineering tools and facility planning techniques can achieve optimum productivity. There is, again, scope for optimization if the practical limitations are extended by a small margin. [1] Layouts are not only concerned with improved utilization of buildings and land but are very much concerned with increasing sales. In the retail environment, layouts must be customer focused and displays should attract the attention of the purchasing public. Hence, it is concluded that productivity is a function of sales, sales is a function of customer satisfaction and in order to achieve customer satisfaction, some capital and some direct losses are inevitable. For now, this study indicated that industrial engineering and facility planning tools and techniques provide a pathway to the organizations towards betterment through employee and customer satisfaction.

\section{REFERENCES}

1. 'Shopping center design using a facility layout assignmen approach', Sherif A. Fahmy, Bader A. Alablani, Tamer Abdelmaguid, DOI: 10.1109/INFOS.2014.7036689, Conference: 2014 9th IEEE International Conference on Informatics and Systems (INFOS)

2. 'Using a productivity function based method to design a new shopping centre', Rafael Suarez-Vega, Jose Luis GutierrezAcuna, Manuel Rodriguez-Diaz, Journal of Retailing and Consumer Services, Volume 51, November 2019, Pages 176-185

\section{AUTHOR PROFILE}

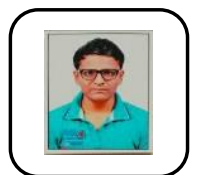

Omkar Gijare A student pursuing BTech in Mechanical Engineering in MIT Academy of Engineering, Pune from 2018. Completed Diploma in Mechanical Engineering from Government Polytechnic, Pune with first class Distinction. Achieved 'Best Project Design Award' in 2018 for the project Automatic Color Sorting System. Achieved Certificate of Excellence in two competitions on mechanical designing. Currently working on Machine Vision System as a mini project. Successfully completed the project Designing and manufacturing of Turbomachines (five experimental setups) at diploma level. Working on a research topic of Designing of Rotary Piston Compressor. Has a working experience of 30 days as an intern. Certification in the course Project Management for managers. Mainly interested in sales and marketing, human resource and mechanical design area.

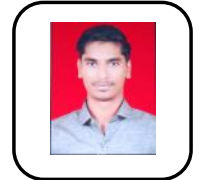

Shubham Khaire A student pursuing BTech Mechanical engineering in MIT Academy of Engineering Alandi Pune. Completed diploma in mechanical engineering from Government Polytechnic Pune with First class Distinction. Working experience in projects such as Prototype of Automatic bottle filling and capping machine using Arduino microcontroller and Design and development of Internal pipe inspection Robot. Achieved Certificate of Excellence in a Competition. Completed an internship for the duration of 30 days. Achieved first rank in second year of BTech in mechanical department. Certification in the course Project Management for managers. Successfully completed the project Automatic Irrigation System for environmental science. Interested to work in mechanical design, automobile, agriculture and manufacturing technology sector.

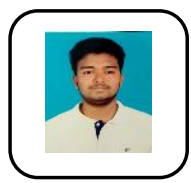

Mohd. Yasin Bagwan A student pursuing BTech in Mechanical Engineering from MIT Academy of Engineering (MITAOE), Pune. Completed Diploma in Mechanical Engineering with distinction from All Indian Shri Shivaji Memorial Society's (AISSMS) Polytechnic, Pune under MSBTE in the year 2018. Achieved Certificate of Excellence in a mechanical designing competition. Completed the course Project Management for Managers from NPTEL and Certified by IIT Rokee for the same. Studying Industrial Engineering \& Management (IEM) and Facility Planning. Successfully completed the project Automatic Guided Vehicle as a minor. Certified specialist in CATIA V5 as a Mechanical Designer. Successfully completed a workshop on Entrepreneurship. The areas of interest are automobile, Designing and Robotics.

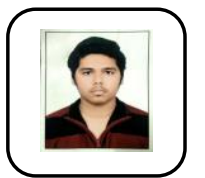

Sahil Srivastava A student pursuing BTech in Mechanical Engineering from MIT Academy of Engineering (MITAOE), Pune. Completed Diploma in Mechanical Engineering with distinction from Y.B. Patil Polytechnic, Pune under MSBTE in the year 2018 Completed Project Management Course for Managers from NPTEL and Certified by IIT Rokee for the same in 2019. Achieved Certificate of Excellence in a mechanical designing competition. Successfully completed the project Automatic Guided Vehicle as a minor. Currently studying Industrial Engineering \& Management (IEM). Working experience in a conveyer manufacturing company. Internship experience of 30 days. Certification Successfully completed a workshop on Entrepreneurship. The areas of interest are Designing and Automation.

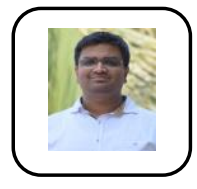

Venugopal Kulkarni Working as Assistant Professor in MIT Academy of Engineering, Pune from June 2016. Associated with Institution of Mechanical Engineers (IMechE), UK since December 2016. Working as Industrial consultant in Chakan, Pune Industrial area for activities like training, quality since 2016. Outstanding Students Chapter Award 2019 by Institution of Mechanical Engineers, UK at AGM, Kolkata. Winner of second prize in national level prestigious 'K.C. Mahindra Award for excellence in automotive design' competition for year 2007. Won first prize in the national level technical paper presentation contest PIONEER-2K6 on 29 and 30th, September, 2006. Presented paper in the national level technical paper presentation event MOMENTUM-07 on 13th March, 2007. Participated in the state level technical paper presentation event on 17th March, 2006. Working industrial experience of around more than four years and teaching experience of more than six years. Worked in industrial sectors such as sales and product development, marketing, technical requirements and quality.

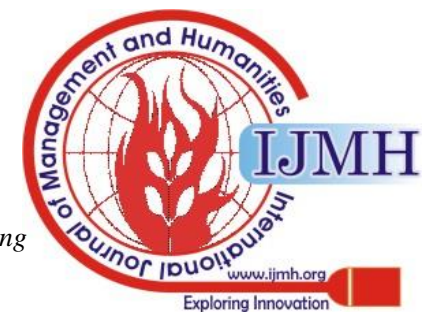

